\title{
The Spatial Morphological Design and Protection of Modern Gardens Around Taihu Lake Under the Perspective of Drones
}

\author{
Wenjie Liu ${ }^{1}$ Pohsun Wang ${ }^{1, *}$ Jie Gu ${ }^{1}$ Jia Tang $^{2}$
}

\author{
${ }^{1}$ Faculty of Innovation and Design, City University of Macau, Taipa, Macau, China \\ ${ }^{2}$ School of Arts, Shanxi Normal University, Linfen, Shanxi, China \\ *Corresponding author. Email: phwang@cityu.mo
}

\begin{abstract}
Based on the perspective of drone overlooking the modern garden of Taihu Lake, this paper analyzes the relationship between modern gardens and Taihu Lake around Taihu Lake, combines the overall spatial form of the garden with the occurrence of history, and formulates a targeted protection strategy for the garden art, history and culture and natural form of the modern garden around Taihu Lake. At the same time, according to the social and economic changes of the surrounding cities, the causes of the choice of modern gardens in the location and the characteristics of spatial form explore the new ideas of the heritage and development of modern gardens around Taihu Lake.
\end{abstract}

Keywords: Ring Taihu Lake, modern garden, space form, protection, planning and design

\section{INTRODUCTION}

\section{A. The origin of modern Chinese gardens}

The origin of modern Chinese gardens, in addition to the ideological basis of ancient public gardens, is deeply influenced by the practice of Western A.D.[1] After the bourgeois revolution in the mid-17th century, in a social environment that promoted democracy and equality, some gardens originally intended for the royal aristocracy were gradually opened to the public, and New York Central Park, built in 1858, became a symbol of the establishment of the city park, thus launching a popular urban park movement.[1] The impact of Western culture has produced a change in the style of Chinese garden creation, such as American style, Japanese style, Russian style and so on. The form of garden-making is also gradually open, with typical western civilization characteristics.[2] China's modern society has been influenced by these styles for nearly a hundred years, and since then there has been a new look in Chinese gardens.

\section{B. The concept of the garden around Taihu Lake}

The core of the Jiangnan region in the Ming Dynasty clear Suzhou, Songjiang, Changzhou, Zhenjiang, Nanjing, Hangzhou, Jiaxing, Huzhou eight capitals, and later by the Suzhou province of Taicang Zhilizhou city.[3] The area is defined by more than 2000 years of concentration in the area covered by a water system in the Taihu Basin.[4] The core of the Jiangnan area is the complete Taihu basin area, which has been concentrated for more than 2000 years and separates the natural landscape from the periphery. The region's natural features and economic culture show the commonality of the region, the core covers the lower reaches of the Yangtze River on the south bank of Taihu Lake and surrounding areas, developed water systems to create the wealth of Jiangnan, but also a review of human civilization.[5] "Taihu Scenic Area Master Plan" (2010-2030) in the scope and nature of the Taihu Scenic Area research scope is based on Suzhou, Wuxi, Changzhou, Huzhou four cities focused on the area around Taihu Lake. Taihu Scenic Area is a natural lake-type national scenic spot with Pingshan far water as its natural landscape characteristics, typical Wu Yue culture, and Jiangnan water scenery as its resource elements. The finishing of modern garden data around Taihu Lake is very important, summing up the relationship between the natural landscape of the garden, the collision of the garden and the lake water with the time in space, and interpreting the historical culture and spatial changes of the garden in history.

\section{THE DEVELOPMENT STATUS QUO OF MODERN GARDENS AROUND TAIHU LAKE}

The modern gardens around Taihu now mainly include Yixing City, Wuxi City, Suzhou City, Wujiang City, Huzhou City, Changzhou City, and Jiaxing City ("Fig. 1"). The garden of Taihu Lake mainly emphasizes conforming to the natural formation of the landscape environment and the design of the garden is adapted to local conditions. This is also the "garden" in 
particular emphasis on the relationship between natural landscapes and waters. [6] The modern gardeners of Taihu Lake conform to the terrain, respect nature, and make full use of the countryside landscape of Taihu Water and mountain forest land, build by the relationship between mountains and waters, and refine and sublimate the natural beauty by artificial means. The Chinese classical garden pursues the use of the height of the terrain to look out over the distant landscape, highlighting the garden's garden-making skills. [6] The modern gardens around Taihu Lake have inherited the valuable experience of Chinese classical gardens in site selection, cleverly relying on the relationship between the island's natural terrain and the opening of the lake shoreline, flexible choice of garden base, forming a wealth of visual landscape and spatial experience.[1] The construction of modern gardens around Taihu Lake cannot be separated from the socioeconomic background, in the early 20th century, under the strong promotion of industrial thought, there have been several outstanding national industrialists, such as Wuxi City in the early modernization of the development of Rongshi, Yang, Xue, Wang, Qin, Tang's and other private capitalists, these national capitalists in Wuxi City industrial operations, the use of Wuxi's unique landscape advantages, cleverly borrow the scenery of Taihu Lake to build modern gardens, including Meiyuan, Jinyuan, Taihu Villa, Hengyun Mountain Resort and so on. In the Nanxian area of Huzhou, the opening of Shanghai in 1843 brought great business opportunities to Nanxun, and $70 \%$ of Shanghai's nearly 100 silk trade lines were opened for Nanxian people, relying on huge international demand, and Nanxun silk merchants "turned their hands, and the rich could stand up."[7] Rich businessmen after the money began to build private gardens, because of the local respect for Confucianism, Nanxian modern gardens also inherited the traditional garden-making methods, the water, and mountains as a garden view.[8] Also, the existing modern gardens in Nanxuan are more unique in their reaction to Western influence, and the inherited classical garden features constitute the characteristics of the Chinese and Western characteristics of the style.

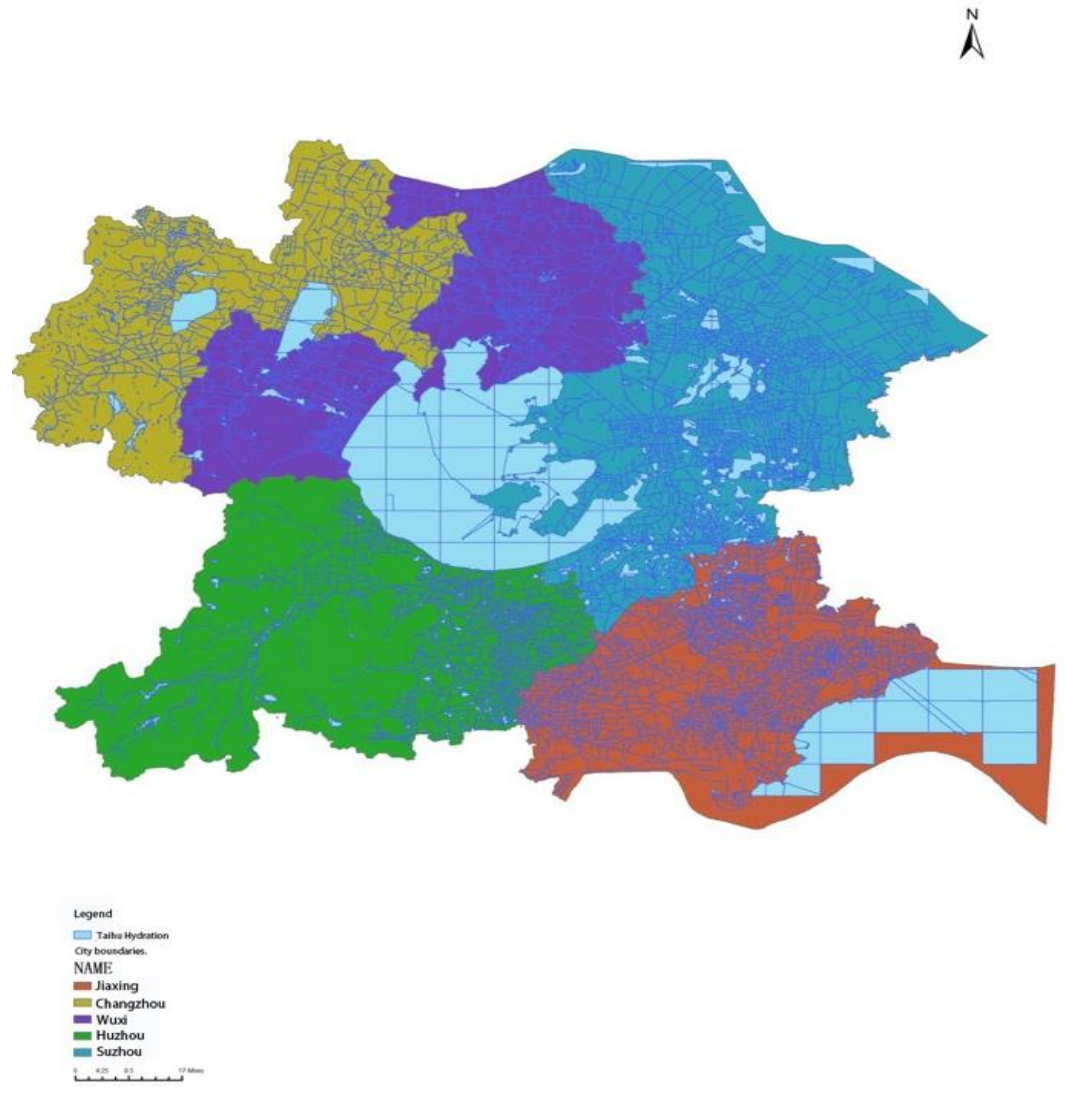

Fig. 1. Distribution of urban clusters around the modern gardens of Taihu Lake.

Suzhou City is one of the surrounding cities around Taihu, and Suzhou City gardens are mainly classical gardens, but through field research, it was found that some classical gardens in Suzhou in 1840-1919 were 
extensively destroyed and afterward repaired, such as Suzhou Yanjia Garden. [9] Suzhou also has some modern gardens to continue the classical garden experience gardening methods and has the impact of modern garden Western culture, for which I through practical research in the follow-up modern garden status quo classified. In addition to Wujiang City, Yixing City, Changzhou City and Jiaxing City, such as "Fig. 2", through the analysis of geographic information system (GIS), you can find the relationship between the surrounding city groups and Taihu Lake, Changzhou City and Jiaxing City, relatively speaking, when the park should be built with the Taihu water system relationship is weak, Suzhou City, Wuxi City, Huzhou City from Taihu Lake, the number of garden creation, is an important analysis area of this study. The definition of the scope of modern garden protection around Taihu Lake draws on the demarcated areas in the Master Plan of Taihu Scenic Areas (revision), "the protected areas are designed to maintain the natural environment and ecological balance of scenic spots, maintain the coordination of landscapes inside and outside scenic spots, prevent pollution and control construction activities." The definition of its scope consists of three parts:
- Scenic area perimeter - based on reference to the 86th edition of the "Plan" peripheral protection zone boundaries, Combined with the current situation of scenic development, adjust the scope of scenic land. The road, Taihu water system, and mountains and other combined with landscape design planning clear the boundaries of scenic land. Taihu Waters - the waters of Taihu Lake outside the scenic area are included in the protection zone.

- The area around Taihu Lake - the land area of 200 meters to 500 meters along the lake is designated as a protective zone. In "Fig. 2", the black dotted line in the figure is the "Taihu Scenic Area Master Plan" (revision) scenic area planning scope. The protected area around Taihu Lake is 200 meters to 500 meters, which is the key area of the study and will explain the relationship between hydration and modern gardens in the surrounding cities, making the study more holistic.

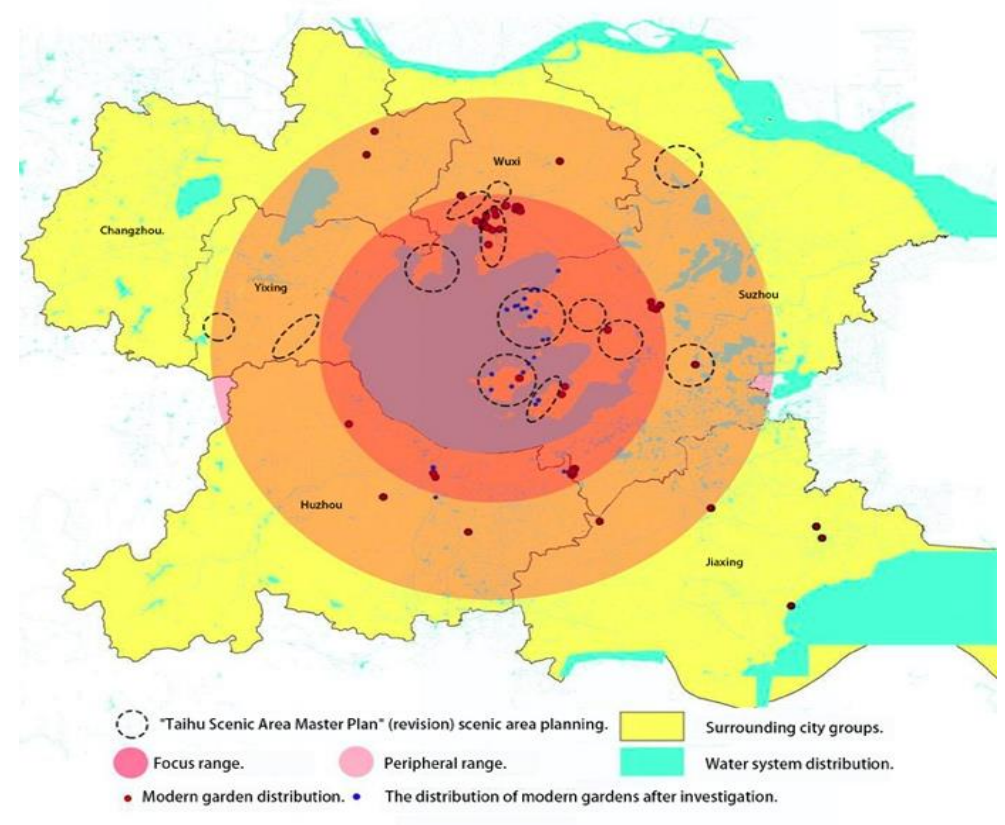

Fig. 2. Regional planning of modern garden attractions around Taihu Lake and an analysis of the scope of this study.

\section{ANALYSIS OF THE SPATIAL FORM OF MODERN GARDENS AROUND TAIHU LAKE}

The research of the modern gardens around Taihu Lake is relatively small, and this preliminary study of the modern gardens around Taihu Lake, combined with the data, summarizes the status quo of modern garden reservations in five urban areas. In Wuxi City, it has a total of 38 modern gardens, and Meiyuan, Taihu Villa, Jinyuan, and other gardens are well-preserved with natural form. 
There are 11 modern gardens in Suzhou City, the majority of modern gardens in the East and West Mountain Scenic Areas, 17 modern gardens in Huzhou City, the majority of modern gardens in Nanxun District, and the center of Huzhou City is dominated by modern gardens. Data are obtained by aerial, and the landscape image model is processed after postprocessing to sort out the spatial landscape pattern between Taihu water and modern gardens.

On the data collection and garden type summary, the modern garden around Taihu Lake has unique garden space characteristics. Through the summary, the modern gardens around Taihu Lake are classified:

- First: Mountain and water systems are the key elements of garden design. A curved water system landscape forms between mountains. The garden is designed according to this naturally formed landscape. Plants, Taihu stone, bridges, etc. all use local garden-making techniques to form the beauty of nature." Fig. 3" is the ancient Changyuan, located in Jinting Town Linya Village kiln on the natural village, the original temple of the city, commonly known as the Shuangguanyin Hall. Founded in the Southern Song Dynasty, it was rebuilt between 1821 and 1850 and renovated in 1995 . The park brand square, Cihang Hall (Guanyin Temple), would like to serve as Buddha, Guanyin Yusa, the city master, and so on. Existing 1848 monument, the garden is located in the environment of mountains and waters, beautiful scenery, with the charm of nature, classical and modern fusion. The ancient Changyuan is located between the mountains and rivers, the river line of Taihu Lake and the mountain form a mountain and river landscape, which is the characteristics of the modern garden around Taihu "mountain river" landscape, is a ribbon distribution, the river, and bridge between the bridge, in line with the changes of the river produced by the landscape characteristics of the landscape. The ancient camphor botanical garden continues the classical garden-making techniques. The ancient camphor botanical garden continues the classical garden-making techniques, designing the garden according to the natural geographical phenomenon, using the ancient camphor tree as the main view of the garden, and designing the garden according to the trend of the river. Through the angle of looking down, we can see the spatial relationship between the mountains and waters, holding the mountains and waters.


Fig. 3. Aerial 2 panoramas and garden analysis of the ancient Camphor Botanical Garden in Suzhou City.

- Second: The garden meets the lake. The garden view focuses on Taihu Lake, borrowing the unique landscape of Taihu Water to add beauty to the garden. The spatial layout is open and closed, and the use of mountains, plants, buildings, lakes, and paths is clever, conforms to the terrain, and makes proper use of the original lake water, so that it fully displays its characteristics and essence of beauty. The representative garden is the Wuxi Shantou
Scenic Area as shown in "Fig. 4", using the method of "just because of borrowing", followed by Suzhou Qiyuan, Wang Wang Temple, etc., which continues the classical garden tradition garden style, the architecture of the garden has a typical Western-style, and the collision of modern building materials and technology, and all reflect the natural features of Wuxi Taihu Garden in modern times. 


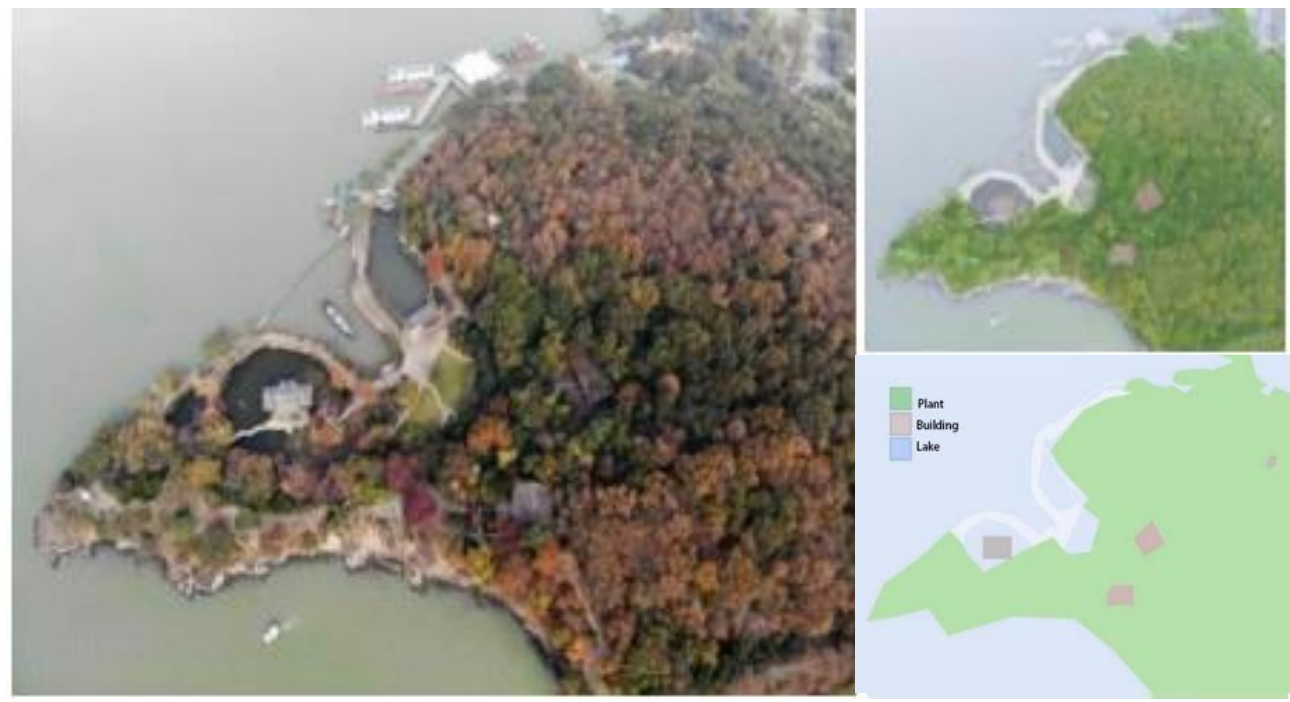

Fig. 4. Aerial capture of Hengyun Mountain Resort and Garden Analysis Map of the Shantou Scenic Area in Wuxi City.

- Third: landscape house garden mutual seepage type, between the surrounding plants, lake water, Taihu stone garden elements of the construction of buildings, the use of nearborrowed, far-borrowed garden art, landscape house garden mutual seepage garden is mainly reflected in the garden memory left over from history, belongs to the typical landscape with cultural characteristics. In "Fig. 5", it is Qian
Park, and Qian Garden's trick is to borrow the view from near. For example, surrounding plants, lake water, Taihu stone, etc. , the use of garden elements to construct scenery. Qianyuan also retains modern history and culture, adding Western culture to the garden. The garden memory leftover from history is also the characteristic culture of the modern garden around Taihu Lake.

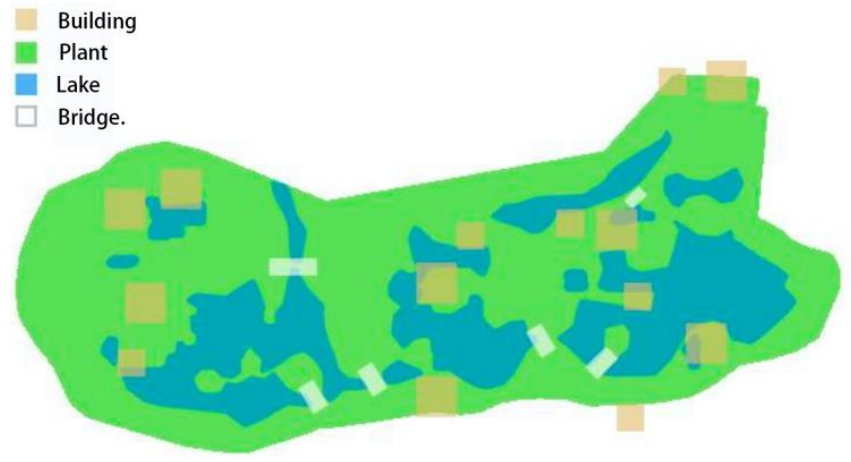

Fig. 5. The distribution status quo of Huzhou Submarine Garden and Classical Garden Lotus House.

\section{THE DESIGN SIGNIFICANCE OF THE PROTECTION AND DESIGN OF MODERN GARDEN SPACE FORM AROUND TAIHU LAKE}

A. Modern gardens in the Taihu area are an important part of Chinese gardens and historical heritage, and the study of their spatial morphological features is helpful to the collective protection, inheritance, and development of culture in the Jiangnan region

The area of Lake Tai has special natural geography and social and cultural background, the lake landscape is an important element of gardens in Jiangnan area, and the modern garden of the Lake area of the lake surface, green space, and artificial architecture in nature are in one, showing the characteristics of the giant ringshaped space form, at the same time, as the core of modern gardens in Jiangnan region, the germination and development of modern Chinese gardens have a certain leading role.[10] The evaluation and protection theory of modern gardens in the Taihu area is scattered on the whole, and the garden collection and data are more isolated in the geographical analysis, and the modern gardens carry the characteristics of the 
combination of new tides and traditions, should be a comprehensive, complete and historical analysis of its spatial form, the formulation of scientific and effective planning model, and help to enhance the quantitative evaluation and analysis of other garden resources in China, as well as in scientific protection to inherit and develop.

\section{B. The modern gardens around Taihu Lake are facing the impact of urbanization development, and the research and protection planning of its spatial morphological features are conducive to the sustainable development of the regional ecological environment}

The modern gardens around Taihu Lake are faced with the impact of urbanization development, and the research and protection planning of its spatial morphological features are conducive to the sustainable development of the regional ecological environment. The urban pattern of "one side of a thousand cities" is gradually formed, the natural modern gardens around Taihu Lake are gradually affected by urban architecture, residential areas, hotels, and resort tourist areas continue to be built, the cultural characteristics of modern gardens are gradually ignored, and the recognition degree is reduced. This analysis of the spatial pattern characteristics of modern gardens around Taihu focuses on Wuxi City, Suzhou City, Huzhou City, Changzhou City and Jiaxing City five urban areas, actively excavating the dynamics of the modern gardens around Taihu, the modern gardens in the Jiangnan area of modern Shuncheng, through the infiltration of modern historical and cultural horizontal vertical comparison between the urban groups around Taihu Lake, excavating the uniqueness of modern gardens, the overall architectural density of contemporary cities, urban distance and modern garden spatial relations proposed design strategies.

In the history of modern architecture and urban planning, the research paradigm of "frontier, edge and boundary" is regulated, and the sustainability of cities is put forward.[11] The construction of modern gardens living between cities should take the initiative to find new links between cities, construct its border protection plan, fully understand the natural landscape relationship of the overall spatial form of modern gardens in the Taihu area, form the overall garden planning scheme management adapted to the development of Taihu area, integrate the fast-growing urban architecture with it, and enhance the sustainability of the ecological environment in Jiangnan area.

\section{CONCLUSION}

This study combines the overall spatial form of the garden with the occurrence of history through the perspective of a drone, formulates the targeted protection strategy for the garden art, history and culture and natural form of the modern garden around Taihu Lake, and explores the new ideas of the heritage and development of the modern garden around Taihu Lake. The modern garden of Taihu Lake embodies the characteristics of "garden scenery" as a natural product, which not only reflects the superb skills left over from the ancient man-made garden but also is a witness of the history of the modern period and a manifestation of the intersection of Chinese and Western cultures. To enhance people's awareness of garden culture in modern times, and to preserve the garden elements and traditional garden design in modern times. The digital model of the garden is constructed by the UAV (Unmanned Aerial Vehicle) survey technology, and the electronic archive of the modern garden around Taihu Lake is established, which provides the theoretical basis for the investigation of the relics of the modern garden landscape around Taihu Lake.

\section{References}

[1] Zhu Zhenjun, Y.C., Wang Xin \& Ge Yiying, On the historical status of Wuxi's modern gardens. Chinese garden, 2017. 10: p 47-51.

[2] Junzhen, Z., The history of modern Chinese gardens. 2012 : China Building Industry Press.

[3] Xing, F., Jiangnan economy in Qing Dynasty: a typical example of the role of natural environment. The historical study, 2010(9): p. 4-6.

[4] Gao Yifan and F. Jinmin, Taihu Basin in Regional History Research: "Jiangnan" or "Zhejiang West". Anhui history, 2014(4): p. 59-68.

[5] DIng Jijiang, X.X. Wu Xinji, and W. Lei. Study on land Use Dynamics and Management Countermeasures of Scenic spots in the Process of Urbanization - A case study of Taihu Lake Scenic Spot. In China Urban Planning Annual Conference. 2008.

[6] Wufou, J., Gardening. 1957: Urban Construction Press.

[7] Gengmei, X., Lan Yu's interpretation of the same heart record. 2006: Fujian Science and Technology Press.

[8] Weirong, Z., Exploration of nanxun Private Garden in modern Jiangnan Gardens. Journal of Huzhou Normal University, 2016. 38(9).

[9] Yanwen, X., Yan Jia Garden with different scenery. Bonsai: Flower gardening, 2018. 539(10): p. 41-43.

[10] Han Changlai, M.R., Structural characteristics and Functional changes of Taihu Lake water system. Lake science, 1997(04): p. 300-306.

[11] Yishi, L., Frontier, Edge and Border: The Current Trend and Trend of the Study of the History of Modern Architecture in China. Journal of Architecture. 2015(06): p. 63-67. 